\title{
La obra de Jean Renoir como traslación de los postulados impresionistas al lenguaje cinematográfico
}

\section{The work of Jean Renoir like translation of the impresionist postulates to the cinematographic language}

\author{
José Roberto Vila Oblitas \\ Universidad de Málaga. \\ joseroberto@uma.es \\ Vanesa Francisca GuZmán Parra \\ Universidad de Málaga. \\ vgp@uma.es
}

Recibido: 4 de agosto de 2011

Aprobado: 7 de marzo de 2012

\section{Resumen}

El presente trabajo analiza la presencia de técnicas propias del impresionismo en la obra cinematográfica de Jean Renoir. Dicha presencia no sólo se debe a la relación paterno filial de dicho autor con su padre, el pintor Aguste Renoir, sino a una intención premeditada de trasladar el impresionismo al cine.

La metodología seguida para realizar esta investigación se basa en el análisis de la mayor parte de la obra cinematográfica de Jean Renoir, haciendo especial referencia a la película de su filmografía donde todas las influencias del impresionismo son especialmente evidentes, Un día de campo (Une partie de campagne, 1936).

Palabras clave: Cine, Pintura, Jean Renoir.

Guzmán Parra, V., Vila Oblitas, J.R. (2013): La obra de Jean Renoir como traslación de los postulados impresionistas al lenguaje cinematográfico. Arte, Individuo y Sociedad, 25(1) 31-42

\begin{abstract}
This paper examines the application of the techniques of impressionism to the cinematographic work of Jean Renoir. It is not just a question of influence of the parent-child relationship between the author and his father, Jean Renoir has a premeditated intention to translate the impressionism techniques to the movies.

The research is based on the analysis of the cinematographic work of Jean Renoir, with special reference to Une partie de campagne (1936).
\end{abstract}

Key Words: Cinema, painting, Jean Renoir.

Guzmán Parra, V., Vila Oblitas, J.R. (2013): The work of Jean Renoir like transfering of the impresionist postulates to the cinematographic language. Arte, Individuo y Sociedad, 25(1) 31-42 
Sumario: 1. Introducción, 2. Metodología, 3. Influencia del impresionismo en el cine de Jean Renoir, 3.1. Periodo silente, 3.2. Desde la llegada del sonoro hasta el exilio americano, 3.3. El color en el cine de Jean Renoir, 4. Un día de Campo, 5. Conclusiones. Referencias.

\section{Introducción}

Analizando la obra cinematográfica de Jean Renoir, se pueden encontrar numerosas referencias a la obra de su padre Aguste Renoir y al movimiento impresionista.

Se podría entender que esto es debido a la condición de hijo de un pintor impresionista y que sencillamente alude en su obra a recuerdos de su niñez, pero un análisis exhaustivo de su obra puede demostrar que Jean Renoir no sólo pretende evocar su infancia con estas referencias, sino que existe una premeditada intención de trasladar al medio cinematográfico las constantes del movimiento impresionista.

Este interés de Jean Renoir por trasladar al cine técnicas propias de otras artes hace que además de introducir técnicas impresionistas a su cine también utilice técnicas que provienen del teatro o de la literatura.

Para demostrar la traslación que lleva a cabo Jean Renoir, hemos analizado su filmografía completa buscando las obras en las que las técnicas impresionistas se reflejan de forma más manifiesta y hemos procedido al análisis exhaustivo de una de sus obras más representativas que deja patente la intención de llevar el impresionismo al cine.

\section{Metodología}

Como expone Delponti (2007), el empleo del análisis crítico como sistema para estudiar una película, resulta apropiado para ubicar a la obra a medio camino entre el cuerpo creador y el público y así descubrir el significado que subyace y que por consecuencia se transmite. Es por este motivo que el presente trabajo se basa en un análisis crítico exhaustivo de la película Un día de campo. Para contextualizar el trabajo, en la introducción, se analiza la relación del movimiento impresionista en la filmografía de Jean Renoir y el papel concreto que este movimiento tiene en Un día de campo.

Para llevar a cabo este análisis, el estudio se ha basado en el visionado de la totalidad de la obra de Jean Renoir y el análisis exhaustivo de Un día de campo.

\section{Influencia del impresionismo en el cine de Jean Renoir}

\subsection{Periodo silente}

La influencia impresionista impregna el cine de Renoir desde sus inicios con La hija del agua (La fille de l'eau, 1924), película protagonizada por Catherine Hessling, que además de ser la primera mujer de Jean Renoir, había trabajado como modelo para su padre. La película se rodó en el bosque de Fontainebleau, que era un escenario 
recurrente en la obra de Renoir padre. Pero lo que en un principio parece un intento de Jean Renoir de seguir los pasos de su padre llevando las técnicas impresionistas al cine, sacando las cámaras al aire libre para captar en plena naturaleza algunos momentos efímeros de belleza, acaba siendo un melodrama muy influido por D.W. Griffith.

Sus siguiente películas mudas persiguen un progresivo alejamiento de la realidad con una vocación claramente vanguardista y, a pesar de adaptar grandes clásicos de la literatura como Nana (Nana, 1926) y La Cerillera (La petite marchande d'allumettes, 1928), Renoir opta por una técnica más cercana al teatro de marionetas que a cualquier movimiento cinematográfico existente, con ello lo que pretendía era ir reinventando la realidad con los elementos que le proporcionaba el lenguaje cinematográfico, al igual que hacían los pintores impresionistas con sus nuevas técnicas pictóricas.

\subsection{Desde la llegada del sonoro hasta el exilio americano}

Con la llegada del sonoro, Jean Renoir se alejó de movimientos de índole vanguardista con la intención de plantear propuestas de cine social. Es éste su periodo de mayor activismo político: publicó artículos en varios periódicos y revistas de la izquierda francesa (Faulker y Duncan, 2010: 49), dirigió películas a favor del cambio social como El crimen de monsier Lange (Le crime de monsier Lange, 1936) y realizó La vie est à nous (1936) por encargo expreso del partido comunista francés (Faulker y Duncan, 2010: 71-73). Renoir manifiesta así una clara predilección por las clases modestas frente a la alta burguesía a la cual tendía a satirizar. Utilizando técnicas de índole naturalista, como la utilización de escenarios naturales, incluso en el ámbito urbano, observándose ciertas reminiscencias con la obra de Erich Von Stroheim.

Aún así, su cine seguía teniendo un afán innovador, lo que es evidente en obras como La Golfa (La chienne, 1931), que es una obra pionera en el uso del sonido directo. Se manifiesta su afán de reconstruir la realidad en vez de captarla directamente, en el hecho de que dicha película se abre con la narración de la historia a través de un teatro de marionetas. Con ello Jean Renoir nos advierte de que lo que estamos viendo no es un espejo fiel de la realidad, sino una ficción cinematográfica, concepto clave para comprender las intenciones de Renoir en toda su obra ya que lo que busca es una reconciliación entre la teatralidad y el realismo. Este aspecto es muy importante para comprender el carácter impresionista del cine de Renoir, ya que deja patente que no le interesa captar fielmente lo que observa sino presentarnos su visión subjetiva de las cosas, al igual que hacía su padre con los cuadros.

En sus siguientes obras refina su puesta en escena de forma definitiva, logrando eliminar todo atisbo de teatralidad mediante un uso de la profundidad de campo. Otorga una mayor fuerza plástica a la escena y consigue un efecto de composición pictórica que potencia la fuerza narrativa de cada una de las secuencias, lo que permite mayor libertad a sus intérpretes para así poder utilizar toda su expresividad corporal.

En Toni (Toni, 1935) nos encontramos con una película neorrealista, en la que se contrapone un rodaje desordenado que Renoir organizó en la mesa de montaje, con una férrea planificación en las escenas más importantes de la película (Casas, 2010: 76). 
Con esta película Renoir plantea una obra cercana a los planteamientos impresionistas, con actores no profesionales y con un tono aparentemente improvisado, rodado además en la Provenza, concretamente en la zona de Aix-en Provence, marco predilecto de la pintura de Paul Cézanne (Monteverde, 2010:64).

La gran ilusión (La grande illusion, 1937) es una de las cumbres de su carrera, un sentido alegato antimilitar que fue criticado por mostrar a los alemanes con excesiva benevolencia. Hecho que se debe a que Renoir no muestra interes en hacer un alegato a favor del ejercito francés, sino que trataba de mostrar lo absurdo de la guerra, porque en ella luchan hombres que en otras circunstancias hubieran sido amigos. En la película se notan más las diferencias de clases que las de nacionalidades, contraponiéndose así dos conceptos diferenciadores del ser humano: nacionalidad y clase social.

$\mathrm{Al}$ año siguiente Renoir vuelve adaptar una obra literaria con La bestia humana (La bête humaine, 1938) basada en la novela de Emile Zola. Renoir se reserva un pequeño papel en la película, anticipando su papel protagonista como Octave en la regla del juego (Wild, 2005: 113).

La regla del juego (La règle du jeu, 1939) es uno de los mejores ejemplos que se pueden encontrar en el cine de Renoir sobre su concepción de la realidad como algo relativo. Toda la película es un juego de espejos, donde Renoir mediante el uso de la amplitud de campo trata de captar la complejidad de la vida. La cámara, como el lienzo del pintor cuando sale a la naturaleza, es la espectadora pasiva de la acción, pero el director al igual que el pintor tiene la potestad de reflejarla según sea su visión de la misma. La película empieza como una especie de vodevil de apariencia más bien ligera, para poco a poco ir convirtiéndose en un reflejo amargo y cargado de nostalgia de la sociedad de la época.

Ya en Estados Unidos realizó varias películas a cargo de los grandes estudios logrando algunas obras destacadas como Esta tierra es mía (This Land Is Mine, 1943), Memorias de una doncella (The Diary of a Chambermaid, 1946) o Una mujer en la playa (The Woman on the Beach, 1947), a pesar de ello, debido al control de los productores norteamericanos estas obras son menos personales y seguramente eso provocó su retorno al cine europeo.

\subsection{El color en el cine de Renoir}

En El río (The River, 1951) volvió a notarse de forma clara la filiación impresionista de su director que utilizó actores amateurs o muy poco conocidos ya que quería acentuar la importancia de la naturaleza en la vida. Esta película es muy importante para comprender el posicionamiento de Renoir como cineasta impresionista, ya que por primera vez puede utilizar el color que, mediante la maravillosa labor de Claude Renoir como director de fotografía, consiguió captar los colores mágicos que exigía este poema visual luminoso y perturbador.

En palabras de Jean Renoir: "El Río es una especie de apunte sobre la vida de una familia inglesa en Bengala. No hay relato, ni principio, ni fin. Es como si se hubiera recortado un fragmento de la vida de un grupo humano sin pretender hacer de él una historia" (Renoir, 1974: 223). Definiendo así su película Renoir nos confirma de 
forma categórica su vocación impresionista ya que no trata de contarnos algo con su obra sino que pretende captar un instante, mediante su plasmación fílmica.

La propia elección del tema es netamente impresionista, con esta película se puede permitir captar la propia realidad a través del reflejo del agua, experimentar con la luz y con los colores a su antojo, rodar en plena naturaleza y, dada la ligereza aparente del argumento, poder prestar más atención al conjunto de la obra que a un detalle concreto.

Por supuesto en la película también se ofrecen todo tipo de contrastes, característica tan propia en Jean como en Auguste Renoir: una fiesta profana occidental frente a un ritual hindú, adolescentes contrapuestos con adultos, muerte contra vida y la gran novedad de la película que radica en la contraposición de colores.

El interés de Jean Renoir por el mundo del teatro y por la representación del teatro en el cine queda patente en tres películas que realizó desarrollando esos conceptos: La carroza de oro (La carrozza d'or, 1952), French Cancan (French Cancan, 1954) y Elena y los Hombres (Elena et les hommes, 1956). Tras El Rio el cine de Renoir tiene un giro visual y expresivo marcado por el uso del color con un claro sentido pictórico (Vizcaino Martinez, 2011: 74).

En la carroza de oro nos encontramos con una teatralidad heredera de la comedia dell 'arte aunque también se pueden rastrear diversas influencias de la pintura. French Cancan es una de sus obras donde la influencia impresionista se puede ver más claramente y por último Elena y los hombres es una especie de opereta ligera, que reflexiona sobre la representación y las apariencias (Latorre, 2010:87).

French Cancan supone toda una declaración de principio, así como un homenaje al impresionismo y concretamente al universo de Tolousse-Lautrec. Se realizan referencias directas a obras impresionistas, especialmente de Tousse-Lautrec, pero también de Auguste Renoir y Edgar Degas. Al igual que ocurre en otras de sus obras, su filiación impresionista no debe de buscarse tan sólo en la referencia directa a cuadros, sino en la propia realización.

Esta película homenaje al music hall parisino cuenta con actuaciones estelares de Edith Piaf y Mario Juillard, y contiene algunos elementos muy interesantes desde el punto de vista de la realización.

Es destacable una de las escenas finales en la que contrapone planos de un baile multitudinario con un casi primer plano de Jean Gabin. Esta escena es impresionante no sólo por la capacidad expresiva del actor (que es capaz de soportar un contraplano de una multitud de bailarinas captando el interés del espectador hacia él) sino por la elección de Renoir que sitúa a Gabin en un escenario neutro (sentado en una butaca con una pared detrás) mientras se desarrolla el resto de la acción en un montaje cada vez más frenético que combina las bailarinas con las reacciones del público, consiguiendo con este montaje un ritmo de colores muy similar al de los impresionistas.

En esta secuencia utiliza unas banderas de Francia situadas en la parte de arriba del encuadre para crear un recorrido cromático en los planos generales, para luego continuar ese recorrido en los planos medios mediante una barandilla de color rojo donde se sitúa la orquesta en la parte de arriba del escenario, sigue con los planos de las bailarinas donde predomina el color rojo, utilizando incluso unas flores rojas que llevan algunos del público en el ojal para componer el plano, en los planos generales 
del público las cortinas rojas de escenario también ejercen de guía visual.

Para cerrar la secuencia contrapone toda la sensación de moviento generada con un primer plano de Jean Gabin solo y casi inmovil sentado una butaca que también es de color rojo. Finalmente, de modo casi imperceptible primero y luego de modo notorio Gabin comienza a moverese para finalmente bailar y acabar uniéndose a la gran fiesta final.

Al final de su carrera realizó Almuerzo en la hierba (Le déjeuner sur l'herbe, 1956) volviendo a los escenarios y temas de su padre que ya había tratado al principio de su carrera en La hija del agua.

\section{Un día de campo}

La conexión de esta película con el mundo pictórico de Auguste Renoir hay que buscarla en el propio momento de la gestación del proyecto, ya que se antoja imposible que Jean Renoir quisiera adaptar un relato de Maupassant sin tener en cuenta la importancia de este fabulista en una parte importante de la obra de su padre. August Renoir descubre la Grenouillère en 1868 y desde entonces volverá allí para pintar de forma habitual, incluso en compañía de otros compañeros impresionistas como Monet. El lugar es descrito por Maupassant en el cuento La Femme de Paul, era el sitio habitual de reposo de los Parisinos cuando iban al campo en las festividades.

El determinar que esta película es impresionista es algo que no viene dado exclusivamente por su temática, o por la continua evocación de los cuadros de su padre, sino por la propia estructura interna de la obra (Quintana, 1998: 132).

Antes de empezar a analizar esta obra convendría puntualizar un par de analogías que estableceremos entre el cine y la pintura, y que son esenciales para comprender esta traslación del impresionismo al cine. Consideraremos que lo que en pintura es el dibujo en el cine es el guión y que el color de un cuadro es la puesta en escena en la película. A partir de estos paralelismos comenzaremos comparar esta obra con las de su padre.

En los cuadros de su padre el dibujo era algo que en apariencia tenía poca importancia, pero que en realidad era el armazón que sustentaba todo el poder de sus colores; esta apariencia de inanidad del dibujo venía provocada porque Auguste Renoir no trataba de captar la forma exacta de la naturaleza, sino la impresión de un momento concreto de la naturaleza ya que estaba obsesionado por captar sus formas cambiantes. En la película, Jean Renoir parte de un guión perfectamente estructurado, generado a partir de una base literaria muy sólida, para hacer una película que da la sensación de estar totalmente improvisada.

Auguste Renoir pintaba sus cuadros en plena naturaleza y éstos podían ir mutando según variara la luz o las condiciones climáticas, provocando pequeñas variaciones en el esbozo inicial, pero sin llegar a cambiar nunca el armazón principal. Esto también ocurre en esta película, ya que como durante el rodaje cambiaron las condiciones climáticas, Renoir tuvo que hacer ligeras variaciones en los diálogos, para así poder captar una impresión de la naturaleza de la mejor forma posible.

En construcción de personajes, se manifiestan contrastes usuales en Renoir, por un lado los habitantes de la ciudad y por otro los del campo. Aunque en este caso los 
personajes están planteados de forma satírica, casi como caricaturas. Dicha contraposición ya estaba apuntada en el relato de Maupassant, pero Renoir lo matiza un poco puesto que estereotipa maliciosamente los personajes del marido y del pretendiente y muestra mucho más respeto por los canotiers (remeros). Este hecho podría considerarse derivado de sus ideas políticas ya que siempre mostró más simpatía por las clases modestas que por la burguesía de cualquier tipo. Por otro lado, al igual que su padre sentía un profundo respeto por la condición femenina. Por ejemplo, el personaje de la madre en el relato de Maupassant es descrito como una inmensa masa de carne, sin embargo, Renoir muestra su carnalidad como reflejo de una sensualidad voluminosa, cercana a la fascinación que sentía Rubens por los cuerpos femeninos robustos.

Los canotiers actúan como faunos modernos a la caza de sus presas, pero mientras que en la obra original tan eran sólo simples estereotipos en la película son dos seres contrapuestos que preparan una maquinación; siendo uno un libertino despreocupado y el otro un individuo extrañamente melancólico. Además para acentuar su retrato de tipologías sociales, no duda en introducirles rasgos caricaturescos como el bigote sofisticado de Rodolphe o la ligereza de sus ropas.

Esta teatralidad en el dibujo de los personajes también se ve reflejada en la puesta en escena, donde aunque aparentemente los personajes se mueven libremente, en realidad esta impresión es fruto de una reconstrucción de la realidad mediante el traslado de los procedimientos propios del teatro a un ámbito distinto como es la naturaleza. Simplemente con observar las entradas y salidas de los personajes a la escena nos daremos cuenta de que lo hacen por los laterales. Además en gran parte, sus movimientos son muy cercanos a la danza en algunos casos o a una teatralidad exacerbada en otros.

La ligereza que trasmite Une partie de campagne la sitúa dentro de las obras de Jean Renoir que nos transmiten un sentimiento de amateurismo. Este naturalismo y ligereza de la obra no es fruto de una inspiración casual, sino de un trabajo de reconstrucción de la realidad mediante la destrucción progresiva de todos los elementos que pudieran delatar la existencia de ese esfuerzo llevado a cabo en la puesta en escena. Renoir busca lo verdadero a través del artificio, mediante el contraste entre lo natural y lo construido, sobretodo al contrastar la naturaleza con la teatralidad de las interpretaciones y la puesta en escena. 


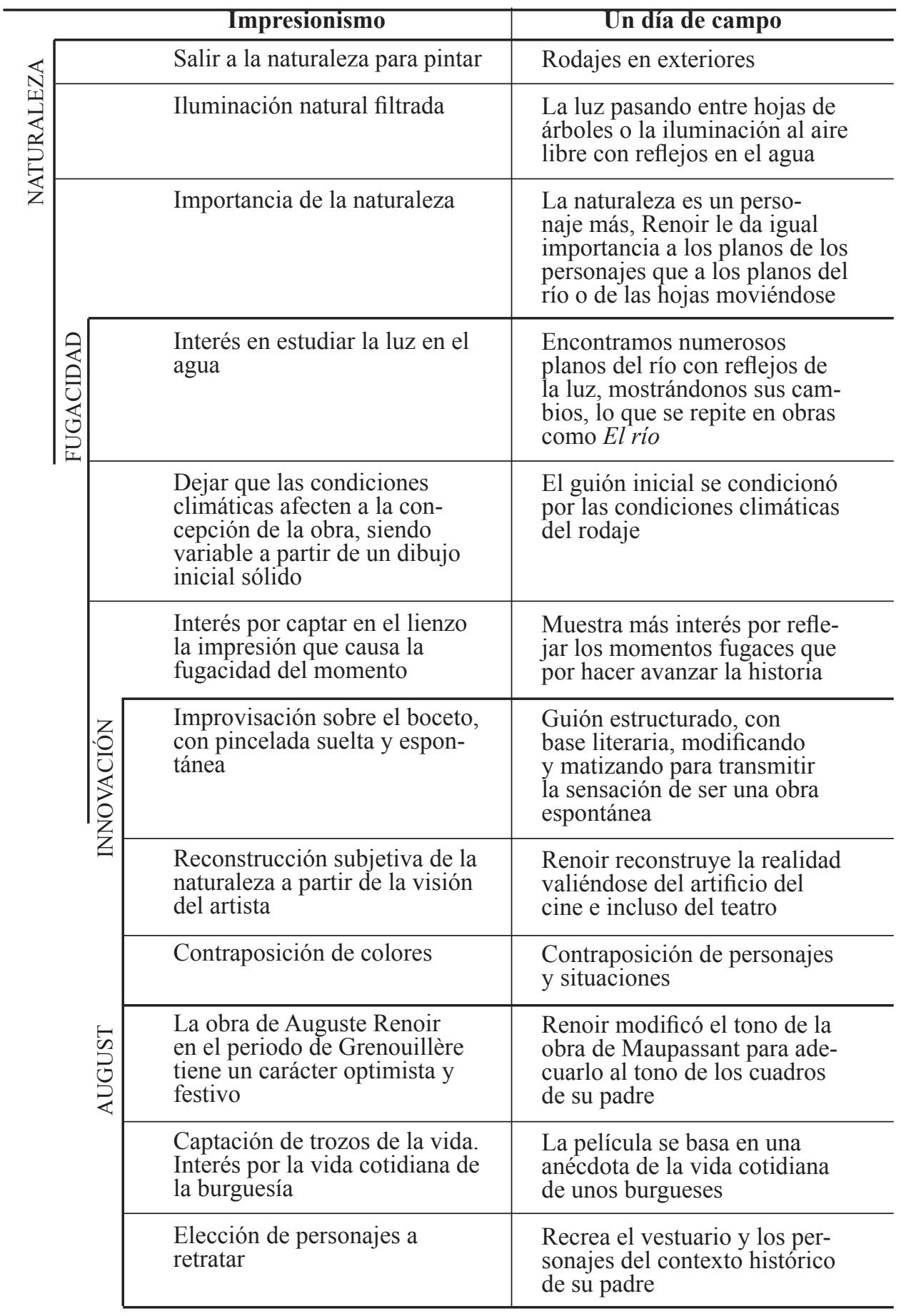

Tabla 1. Características formales del impresionismo presentes Un día de campo. 
En la tabla 1 podemos ver algunas de las características de la pintura impresionista presentes en Un día de campo, a estas características habría que añadir la cita constante de obras de su padre reconstruidas en secuencias cinematográficas.

Existe una iconografía impresionista en el modo de plantear las escenas, siendo la composición de muchas de ellas de tipo pictórico y sobre todo en la importancia que se le da a la naturaleza, que en la puesta en escena adquiere la misma relevancia que los personajes, integrando así a los seres humanos con su entorno.

Este tipo de composición pictórica de las escenas se hace más palpable en aquellas en las que hace una referencia directa a la obra de su padre.

Estas referencias son constantes durante toda la película. La escena del columpio es un reflejo del cuadro de Auguste Renoir El columpio (1876, París, Louvre), donde se establece un singular juego de luz entre figuras y árboles, con agudas transiciones entre azules, rosa y verdes de hecho este cuadro figuró en la tercera exposición que organizaron los impresionistas (Tobien, 1981: 9).

Jean Renoir mantiene en la película el juego de luz que se establece entre las figuras humanas y las ramas de los árboles, haciendo especial énfasis en el efecto que produce en la figura de la muchacha. Además, por las posibilidades técnicas que le confiere el uso del cine en vez de la pintura, puede establecer un juego constante entre planos de cuerpo entero en los que se resalta toda su silueta y planos medios donde se resalta su rostro. Las transiciones de colores que usaba su padre en el cuadro habría que buscarlas en las reacciones de quienes contemplan esta escena: por un lado unos sacerdotes jóvenes que son recriminados por su superior (al tiempo que él también mira a la muchacha), los niños que contemplan la escena de modo cómplice, y por último los canotiers que en ese momento ya están urdiendo sus confabulaciones para acercarse a las mujeres.

El inicio de esta escena ya es toda una declaración de principios del autor. En ella los canotiers abren la ventana, dejando que la naturaleza entre en todo su esplendor, y dando entrada a toda la secuencia del columpio de forma que al iniciarse desde ese punto de vista, aparezca en un principio enmarcada dentro de la ventana como si se tratara de una función teatral.

Se pueden observar reminiscencias con los cuadros que pintó su padre en la Grenouillère entre 1868 y 1869 sobre todo en la forma en la que capta los personajes, la naturaleza y, sobre todo, la luz a través de los reflejos del agua.

Se pueden observar ciertas analogías con el cuadro de La familia Henriot (1876, Merlo, Barnes Foundation) en el modo que retrata a la familia de parisinos en el campo, debajo de ese gran árbol. Y por supuesto se puede observar una referencia constante al cuadro Almuerzo de remeros (1881, Washington, Phillips Collection) en particular, y a todos los cuadros que realizó su padre de remeros en general.

Renoir no se dedica a citar algunos cuadros de su padre con intenciones culturalistas, sino que traslada la temática, la iconográfica, e incluso las técnicas impresionistas al lenguaje cinematográfico, guiado por un sentimiento de búsqueda de lo efímero.

La película es un ejemplo de cine rodado al aire libre, donde el cineasta impresionista sustituye el caballete por la cámara, aunque manteniendo el deseo de mantenerse en plena naturaleza para así poder captarla en toda su plenitud, buscando capturar el instante efímero y las impresiones que le produce. Al igual que los impresionistas, 
está fascinado por la variabilidad de la naturaleza bajo los efectos de la luz. Así, un sentimiento de ligereza surge de contraponer el movimiento y la fugacidad con el estatismo y la solidez.

La puesta en escena teatral perfectamente controlada se opone con la naturaleza cambiante, que va metamorfoseándose conforme se rueda la película. Así los movimientos perfectamente estudiados de los actores entran en tensión con lo efímero, ya que Renoir esta dispuesto a darle tanta importancia a las hojas que se mueven, o a la iluminación cambiante como a la propia historia. Por ello un cambio en las condiciones climáticas provoca unas alteraciones en los diálogos e integrándose en la historia, desemboca en un discurso sobre la fugacidad de la vida.

También es interesante la adaptación que hace del relato de Maupassant., en el que se propone una visión pesimista del mundo, de los sinsabores que puede dar el amor y del dolor que provoca la felicidad cuando tan sólo es un recuerdo. La joven Henriette está condenada a un matrimonio anodino preparado por su padre, pero antes de consumarlo puede saborear los placeres del amor carnal. El carácter solitario, crítico y su profundo desprecio por la humanidad de Maupassant le permitieron mirar su sociedad con distancia y retratarla de forma implacable ( Rodríguez, 2006:73).

Renoir rompe con el pesimismo de la obra de Maupassant, mediante un sentimiento panteísta de la vida. Siendo el acto amoroso parte integrante de la naturaleza, poniéndose de manifiesto en detalles como el canto del gorrión, o con la utilización del río como metáfora erótica mediante la captación del movimiento de sus aguas.

El despertar a la sexualidad de las mujeres se produce cuando están descansando sobre la hierba después de la comida y entran en escena de los canotiers. Esta concepción optimista de la vida está también presente en las obras de su padre (López Blazquez, M., 1995: 24-26), con lo que al modificar el sentido del relato de Maupassant, lo que está haciendo Jean Renoir es ser fiel al espíritu de las obras de su padre en el periodo de Grenouillère que tenían un tono festivo y hedonista.

Así el acto sexual se convierte en un elemento integrador del ser humano con la naturaleza. Siendo el placer algo tan breve como el canto de un gorrión, o como el movimiento de las hojas de los árboles. Estando las pulsiones de los cuerpos humanos en perfecta armonía con el entorno natural (Quintana 1998:140).

El contacto con la naturaleza hace que afloren los impulsos sexuales de los protagonistas, pero tras el encuentro sexual entre Henriette y Henry se pausa la narración mediante planos de la naturaleza (Vidal, 2010:92-93).

El problema viene dado cuando este devenir natural de las cosas es interrumpido por las convenciones sociales. Renoir trata de expresar que cada cual debe de actuar según su naturaleza aunque con ello se rompan las normas establecidas por la sociedad, porque traicionarse a uno mismo sólo puede conducir a la infelicidad.

\section{Conclusiones}

Renoir trasladada al cine muchos de los postulados que seguía el movimiento impresionista lo que no es un caso aislado dentro de su filmografia.

El propio Renoir cuando escribió un libro sobre su padre, afirmó que lo hacía para plasmar los recuerdos de su padre y dejar constancia de cómo le había influido en su 
obra (Renoir, 1962: 8).

El impresionismo propugnaba salir a la naturaleza para captar la realidad de modo directo (Artigas, 2004: 60-61), tal y como hace Jean Renoir en Un día de campo. También es muy propio de las obras impresionistas que el cuadro varíe según las condiciones climáticas, modificándose el dibujo original (Feist, 2006: 16). El guión de Un día de campo se modificó por los cambios de las condiciones climáticas. El cineasta impresionista sale a la naturaleza con su cámara y capta la realidad de modo subjetivo.

Jean Renoir no estaba interesado en captar la realidad tal cual es, sino en mostrar una impresión de la realidad que él percibía, mediante una reconstrucción de la realidad partiendo de las técnicas que le ofrecía un nuevo medio de expresión como es el cine.

$\mathrm{Al}$ igual que su padre y el resto de impresionistas, Renoir innovó las técnicas de su arte para adecuarlas al mensaje que pretendía transmitir. Los pintores impresionistas innovaron a través del color (Feist, 2006: 18), Jean Renoir renovó el cine trasladando al ámbito cinematográfico recursos propios de otras modalidades artísticas como la pintura o el teatro.

Esta renovación renoiriana no debe de entenderse como una pretensión de hacer referencias culturales a otras artes dentro de las películas, sino como un intento de integrar todas las formas de arte adaptándolas al lenguaje cinematográfico.

Al igual que los impresionistas quería hacer llegar su obra a la gente sin necesidad de intermediarios. También es una característica común con su padre la defensa de la idea de que el verdadero artista es el amateur, considerando que en el profesional la obra no surge de la inspiración sino de la necesidad. Renoir hizo una obra destinada al público pero sin plegarse a condicionamiento alguno, lo que provocó que en algunos casos como en el de La regla del juego sufriera la incomprensión de crítica y público. La crítica le rechazaba por ir contracorriente y el público por ser demasiado personal.

La constante contraposición de caracteres que practica, nos remite a la contraposición de colores en la pintura. El modo en que estructura el guión y luego lo va modificando con la puesta en escena, nos ofrece semejanzas con la relación que existe en pintura entre el color y el dibujo. La utilización de la naturaleza en toda su obra de forma recurrente, el modo en que captaba los reflejos de la vida en el agua o la aparición de personajes bajo la sombras de las hojas o ramas son otras variables coincidentes. Todo ello nos indica que estamos ante un auténtico cineasta impresionista.

Incluso, en algunos casos como es el de Une partie de campagne, se llega a producir incluso una nostálgica traslación de temas, de padre a hijo, quedando así Jean Renoir como heredero tanto genético como espiritual de los principios artísticos que defendió su padre.

\section{Referencias}

Artigas, I. (2004). Genios del Arte. Renoir. Madrid: Susaeta.

Casas, Q. (2010) Renoir, el neorrealismo y el instante. Dirigido, 398, 76-77.

Delponti Macchione, P. (2007). Cómo analizar una película: a propósito de La 
Historia Oficial. Área abierta No 18.

Faulkner, C., y Duncan P. (2007). Jean Renoir, conversación con sus películas 18941979. Köln: Taschen.

Feist, P.H., 2006: Pierre Auguste Renoir. Un sueño de armonía. Köln: Taschen.

Monteverde, J.E. (2010). Toni: entre Pagnol y el neorrealismo. Cahiers du Cinema España, 33, 64-65.

Latorre, J.M. (2010). Elena y los hombres. Dirigido, 398, 86-87

López Blazquez, M., 1995: P. Auguste Renoir. Barcelona: Polígrafa.

Quintana, A. (1998). Jean Renoir. Signo e imagen/ Cineastas. Madrid: Cátedra

Renoir, J. (1962). Renoir, My Father. New York (USA), New York Review of Books

Renoir, J. (1974). Mi vida y mi cine. Madrid: Akal ediciones

Rodríquez Martínez, R. (2006). Maupassant, un reportero con aspiraciones literarias: Zer, 21, p 63-74.

Tobien, F. (1981). Auguste Renoir. San Diego (USA): Padre Publishers

Vidal, G. (2010). Amando a los extraños: Carta de una desconocida y una partida de campo. L'Atalante. Revista de estudios cinematográficos, 10. 90-94.

Vizcaíno Martínez, J.C. (2011). Jean Renoir y la máscara de los sentimientos. Dirigido, 409, 74-75.

Wild, F. (2003). Colliding with history in La Bete Humaine: Reading Renoir's Cinecriture. Literature/ Film Quarterly. Vol. 31. No2. Maryland (U.S.A.): Salisbury University. p. 111-118 